\title{
Assessing the Relationship Between Leadership Styles and Job Satisfaction
}

\author{
Sean Ratican \\ Assistant Professor, Business Management \\ Kent State University \\ 4314 Mahoning Avenue NW, Warren, OH USA 44483 \\ E-mail: sratican@kent.edu
}

Received: April 6, $2020 \quad$ Accepted: May 10, $2020 \quad$ Published: July 1, 2020

doi:10.5296/jmr.v12i3.16912ＵRL: https://doi.org/10.5296/jmr.v12i3.16912

\begin{abstract}
The United States workforce is in a period of transition. In April 2020, more than 20 million U.S. workers were out of work. As the economy seeks to reboot, organizations will have to prioritize how they rebuild their workforces. Prior to the global pandemic, there was nearly unprecedented low unemployment within the United States. Firms were constantly seeking ways to stabilize turnover within their organizations to achieve a competitive advantage. This research was conducted to analyze the impact leadership style has on employee job satisfaction. Surveys were collected to determine if there were significant differences in the perceived leadership styles within the industry, a relationship between leadership and job satisfaction, and identify a monetary threshold for which employees would quit. A hybrid of the Vannsimpco Leadership Survey (VLS) and Minnesota Satisfaction Questionnaire (MSQ) was administered to the 92 survey respondents. A single factor, one-way ANOVA was conducted to analyze the participants' responses to the survey. The ANOVA calculations revealed a significant difference among the nine leadership styles $(F[8,819]=12.36, p$ $<.001$ ). A Tukey's Honestly Significant Difference (HSD) test was used to test for significance between the means and found significance in 14 of the 36 pairs.
\end{abstract}

Keywords: Job Satisfaction, Leadership, Transactional Relationships, Organizational Behavior, Transformational 


\section{Introduction}

The United States workforce is in a period of transition. With more than 20 million U.S. workers having filed for unemployment as of mid-April 2020 according to the US Department of Labor, organizations will have to prioritize how they rebuild their workforces. Employees are a vital resource for most organizations. The performance and efficiency of the employees as a whole can often dictate the level of success a company has within the competitiveness of the private sector. As a valued resource, the retention of employees is paramount. As organizations begin to recall workers in the coming months, the identification of talented workers can be essential. To achieve a competitive advantage through the reconstruction of a talented workforce, it is necessary to create an environment of leadership conducive to the attraction, and long-term retention, of valued employees.

Constant turnover within an organization can lead to instability and wasted resources. Training new employees can be costly, and they may be inefficient as they acclimate within the current organizational structure. Companies that thrive in the competitive markets of the private sector do so by relying on competent, efficient employees that produce tangible results in a competitive environment. The loss of these employees can be damaging to a company's ability to compete with other organizations within their industry. Voluntary turnover within an organization can disrupt productivity outcomes, undermine strategic advantages in technology, hinder an organization's culture, and ultimately significantly impact financial performance (Hom, Shaw, Lee, \& Hausknecht, 2017).

Before the global COVID-19 pandemic, organizations across all sectors had fierce competition for employees. In the last month of 2019, the United States unemployment rate was 3.5 percent (US Department of Labor, 2020), which signified the lowest percentage in nearly half a century. The excess of available of jobs, and the limitations of a labor market to fill vacancies, causes high turnover as companies compete for talented employees. Historically, employee turnover in the $21^{\text {st }}$ Century has cost U.S. companies more than $\$ 25$ billion annually, "with the cost of hiring and training an hourly worker at 300 to 700 times the worker's hourly wage" (McKeown, 2010, p. 22). To staunch the ongoing cost of recruiting and training talented employees, companies can look to improve their retention of skilled and valued employees through the deployment of effective leadership.

According to the U.S. Bureau of Labor and Statistics (2020), before the Covid-19 impact caused transition in the workplace, as of February 2020 more than three million workers in the United States had left their jobs voluntarily every month since June 2017. Heading into the first quarter of 2020, the trend was not limited to one specific industry, instead it is indicative of a shift throughout the nationwide workforce. However, typically traditional turnover rates by industry standards omit the reason employees voluntarily leave (Park \& Shaw, 2013). These data are also not indicative of a shrinking labor market. The reality is in fact the opposite, "in which high volumes of hires and separations largely offset each other, and net total employment increases more slowly" (ODJFS, 2018, p. 15). Employees who voluntarily leave current employment do so because they are not engaged or enthusiastic about their jobs (Harter \& Adkins, 2015). 


\section{MlMacrothink}

Journal of Management Research

ISSN 1941-899X

2020, Vol. 12, No. 3

The issue of leadership as an effective means to reduce voluntary turnover received sparse attention in recent literature as compared to the wide coverage of general leadership theories (Waldman, Carter, \& Hom, 2015). Context is critical and understanding the motivations for employees who willingly seek alternative employment is vital to addressing the issue of how to retain valuable members of an organization's workforce. Leadership is predominantly a social endeavor that can be especially impactful in that "leaders, particularly charismatic ones, are highly influential and affect organizational outcomes" (Jacquart, \& Antonakis, 2015, p. 1052). Effective leadership is often based on positive relationships between managers and employees (Bass, Avolio, Jung, \& Berson, 2003).

By identifying the leadership styles most commonly associated with increased organizational commitment and associated with positive job satisfaction, this research sought to establish contextual parameters for effective employee retention. Understanding the paradigm of employee retention and examining the trends in which employees leave current employment is vital to organizational success. There is a need to identify the reasons why employees quit. Understanding these motivations can be critical to an organization's success in developing a stable workforce. Identifying the correlations between leadership style, positive relationships, and job satisfaction can help organizations address the issue of curbing voluntary turnover for talented employees. Identifying the construct of these relationships based on social interaction can also help organizations understand how leadership can have both positive and negative effects on the job satisfaction of valued employees. Voluntary turnover within a workforce can be costly for an organization, both in terms of financial losses and workplace morale. To avoid the monetary and cultural cost of a revolving workforce, it is imperative to identify how leadership can impact job satisfaction.

\section{Purpose of the Study}

The current study was conducted to discover the preferred leadership styles of economic development professionals. There is extensive research on the broad subject of job satisfaction, general employee retention programs, and employee turnover. However, there exists a limited amount of research that has been identified to narrow the scope of retention efforts by determining the impact leadership style has on job satisfaction within the economic development profession. Results of this study can be used to advance the industry's knowledge in regard to the specific impact leaders within the workplace have on the satisfaction of valued employees. An analysis of the data gathered sought to identify the perceived leadership style of the respondents and attempted to identify a relationship between leadership style and increased job satisfaction. The study can also be used to assist organizations that seek to develop attraction and retention programs for valued employees.

Prior to the COVID-19 pandemic, the national job market in the United States had created a surplus of available jobs within nearly every industry. Because the growth of the national workforce had not kept pace with the expanding job market, the competition for quality employees is significant. Employers continue to seek and retain good employees. In order to accomplish this, organizations need to concentrate on the aspects of employment that appeal to their perspective employees. Job satisfaction has a relative impact on employee 
performance, the more content an employee is the more productive they can be. The overall objective of this study was to identify perceptions of leadership styles that can influence job satisfaction, and thus have an impact on the employees' performance.

The landscape of the modern workforce is constantly changing. Employees are an organization's most valuable resource. The desires of competent employees often expand beyond the simple benchmark of financial compensation. Often, the organization's most valuable employees put value in aspects beyond compensation. Culture, communication, and opportunity often trump the paycheck for talented employees capable of similar compensation at alternative firms. In order to retain talented employees, organizations must identify means by which to relate and cultivate employee commitment and job satisfaction. This includes efforts to address intrinsic compensation beyond the quantifiable dollars conveyed for performance. The development of relationships within the workforce can have a positive correlation on an organization's efficiency and performance.

There exists a significant number of studies that pertain to the concepts of leadership and employee satisfaction in general. However, there are few that address specific leadership styles within the context of job satisfaction. The lack of applicable studies that address leadership styles within the context of job satisfaction and retention of economic development professionals creates a need for the study.

\section{Leadership Styles}

Creating an organizational culture is imperative when building a valued and efficient workforce. Leadership styles can vary from company to company, sector to sector, with each style attracting a specific type of employee. To assess the value of leadership, two main theories are examined: transformational and transactional leadership. Although these two styles are far from indicative or comprehensive of the wide variety of styles, transformational and transactional leadership contrast enough to provide sufficient options for most personality types (Bass, 1990). On one hand, "transformational leaders inspire their followers with a positive, value-based vision of the future, transactional leaders rely on clearly defined quid-pro-quo transactions" (Rowold, 2014, p. 368).

The essence of transactional leadership is an exchange between a leader and follower. Transactional leadership theories are rooted in the concept that the relationship between a leader and follower is based on a series of exchanges or implicit bargains (Hartog, Muijen, \& Koopman, 1997). The transactional leader 'recognizes followers' needs and desires and then clarifies how those needs and desires will be satisfied in exchange for meeting specified objectives or performing certain duties" (Daft, 2011, p. 360). This leads to followers receiving rewards for performance in exchange for the leaders benefiting from the completion of tasks (completing the transaction). In order for the transactional nature of this form of leadership to be effective, the leader needs to clearly outline what is expected of the follower, as well as identifying what the follower will receive in return (Hartog et al., 1997).

There are two basic types of transactional leadership: contingent reward and management-by-exception. These types of transactions are differentiated by the leader's level 
of engagement or relationship with the followers. In contingent reward leadership, "the leader and follower negotiate an agreement regarding what rewards or recognition the follower will receive for a specific level of performance" (Pillai, Schriesheim, \& Williams, 1999, p. 681). The rewards or recognition are then provided once the follower completes the task.

Management-by-exception in transactional leadership focuses on mistakes, with leaders only intervening after standards or goals have not been met (Pillai et al., 1999). This can be either active or passive transactional leadership with the leader remaining "passive until problems that need correcting emerge and then intervenes with criticism or reproof" or active by "the leader actively monitors followers' performances to anticipate mistakes or deviations from standards before they become a problem" (Pillai et al., 1999, p. 681). Either type, active or passive management-by-exception, usually result in negative feedback, punishment, and/or discipline. Transactional leadership tends to promote stability rather than promoting change with an organization. These types of leaders are effective by "focusing on the present and excel at keeping the organization running smoothly and efficiently" (Daft, 2011, p. 360). However, if a leader only intervenes when tasks are not being met, transactional leadership can lead to mediocrity in terms of organizational efficiency (Bass, 1990).

Where transactional leadership promotes stability and is generally passive, transformational leadership can promote the type of active, engaged style of organizational culture typically prioritized by a talented workforce. There are very few managers that rely solely on their legitimate power as a source to motivate employees (Bass, 1990). Instead, managers and leaders within the workplace rely on relationships, and transactions with employees to accomplish organizational goals (Maidani, 1991). One of the most influential leadership styles can be transformational leadership.

To contrast the two styles, a transactional leader motivates employees to perform "by contract and reward through an exchange process, allocating rewards for good performance, a transformational leader is more visionary and appeals to the higher order psychological needs of employees of feeling valued and worthwhile in an organization" (Welty Peachey, Burton, \& Wells, 2014, p. 741). Transformational leadership occurs when a leader within an organization pushes their employees to elevate their awareness, and "look beyond their own self-interest for the good of the group" (Bass, 1990, p. 21). This can be accomplished by charismatic leaders inspiring their followers to achieve greater accomplishments, by meeting the needs of their employees, and by stimulating employees intellectually to enhance creativity and increased performance within the workplace (Deichmann \& Stam, 2015).

There is a positive correlation demonstrated between organizational commitment and the tenets of transformational leadership (Avolio, Zhu, Koh, \& Bhatia, 2004). Job satisfaction can be increased as "transformational leadership enhances job satisfaction and team performance at individual and team levels of analysis and directed attention to relevance of trust among team members, in addition to trust in supervisors" (Braun, Peus, Weisweiler, \& Frey, 2013, p. 280). Increased trust leads to increased loyalty. The transformational managers and leaders "are more likely to be seen by their colleagues and employees as satisfying and effective leaders than are those who behave like transactional leaders" (Bass, 1990, p. 21). One of the most appealing 
aspects of a transformational leader to employees is that transformational leaders are "individually considerate, that is, they pay close attention to differences among their employees; they act as mentors to those who need help to grow and develop" (Bass, 1990, p. 21).

In comparing the two styles of leadership, the "transactional leader motivates subordinates to perform as expected, the transformational leader typically inspires followers to do more than originally expected" (Hartog et al., 1997, p. 20). The difference between transactional and transformational leadership styles can be as simplistic as task-oriented or relationship-oriented relations (Hartog et al., 1997). Many effective managers and executives in today's modern workplace do not just use one leadership style, "the best leaders are both transactional and transformational which probably explains why studies have shown consistently high inter-correlations between transformational and transactional leadership" (Pillai et al., 1999, p. 898).

To be an effective leader, both transactional and transformational patterns are necessary to "accentuate not only their abilities to build a vision and empower and energize others, but also the transactional skills of designing structures, control systems, and reward systems that can help people achieve the vision" (Daft, 2011, p. 361). Just because theorists have gone about "contrasting transactional and transformational leadership does not imply that the models are unrelated" (Hartog et al., 1997, p. 21). When used in collaboration, "transactional contingent reward leadership builds the foundation for relationships between leaders and followers in terms of specifying expectations, clarifying responsibilities, negotiating contracts, and providing recognition and rewards for achieving expected performance" (Bass, Avolio, Jung, \& Berson, 2003, p. 215). Which then allows transformational leadership to enhance "the development of followers, challenging them to think in ways in which they are not accustomed to thinking, inspiring them to accomplish beyond what they felt was possible, and motivating them to do so by keeping in mind the values and high moral standards that guide their performance" (Bass et al., 2003, p. 215).

While it is clear that a multilevel approach to managing employees can be beneficial, especially with employees who need the positive reinforcement of transformational leaders combined with the advancement opportunities associated with transactional leadership, the usefulness of one leadership style compared to another still does not address the cause of the issue as to why employees choose to vacate gainful employment. It is a common occurrence to have employees cite their interactions with managers and leadership as a primary reason for quitting a job (Reina, Rogers, Peterson, Byron, \& Hom, 2018). Employees who feel their responsibilities are unclear, or that they lack organizational support for the tasks that are identified, can become frustrated and report lower job satisfaction (Atefi et al., 2014). The managerial influence based on tactics and leadership style has a significant effect on the satisfaction of employees, and their decision to quit or stay within a position (Reina et al., 2018).

Ultimately, the relationship between managers and subordinates matters to employees. If negative, the relationship can cause instability in an organization's workforce evident by the 
fact "that managerial use of pressure tactics was positively associated with employee turnover, and that inspirational appeals were negatively associated with turnover" (Reina et al., 2017, p. 13). Managers can work to improve employee interactions and perception, which "will increase business-unit outcomes, including financial outcomes" (Harter, Schmidt, Asplund, Killham, \& Agrawal, 2010, p. 387).

\section{Leadership’s Impact on Job Satisfaction}

Happy, satisfied workers are efficient and effective workers. Job satisfaction can reflect positive culture, good treatment by superiors, and an indicator of organizational functioning (Spector, 1997). The extent to which employees like, or dislike their positions, job satisfaction is quite simply "how people feel about their jobs and different aspects of their jobs" (Spector, 1997, p. 2). Job satisfaction and organizational commitment are one of the largest factors that contribute to an employee's intention to quit (Kumar \& Eng, 2012; Salleh, Nair, \& Harun, 2012). The less satisfied an employee is within the current position, the more likely that employee is to seek alternative employment (Spector, 1997).

When considering the motivations of employees, the environment and culture of the modern worker must be taken into consideration. Raised in a digital age, the more recent generations of employees "have been raised and socialized with unprecedented levels of positive reinforcement and attention" (Johnson \& Ng, 2015, p. 287). The want and need of positive reinforcement creates a dependence on the stability of a positive manager or leader. Negative emotions can lead to behaviors that result in detrimental effects on both the organization and the employee's health (Spector, 1997). Within the workplace, an employee's self-esteem is tied to the treatment and feedback received from supervisors, negative or abusive interactions can affect the quality of work, increase job-related stress, and result in diminished job satisfaction which can impact employee retention (Atefi et al., 2014; Vogel \& Mitchell, 2017). Most working adults have a negative experience in the workplace at one point in their career that has resulted in leaving a job to get away from a manager who had a negative impact on their employment (Harter \& Adkins, 2015). Organizations that embrace policies "that maximize job satisfaction will likely have employees who are more cooperative and willing to help the organization be successful" (Spector, 1997, p. 72).

Research has indicated a direct link between these opportunities established within cultural conditions, including employee appreciation, role clarity, colleague relationships, upward advancement opportunities, and the performance of an organization (Harter et al., 2010). With common job satisfaction categories such as opportunity, autonomy, and occupational prestige that cross multiple industries, one significant variable to job satisfaction seems to be leadership style (Bogler, 2001). Hence, it would behoove an organization to improve manager relationships through leadership analysis and cultural adaptations. One way in which an organization could mitigate the effects of negative supervisor interactions by "creating an environment that enhances and maintains adaptive and safe interactions among employees, organizations can reduce employees' overdependence on their supervisor for the need to feel valued" (Vogel \& Mitchell, 2017, p. 2247).

Although, it is important to note that as with social groups and situations, when considering 
the workplace, 'there are people who want to be 'managed' and those who want to be 'inspired' and the choice between the two is a matter of ongoing negotiation between the follower and the leader" (Martin \& Epitropaki, 2001, p. 260). Both transformational and transactional leaders can be effective in mitigating an employee's desire to quit (Wells \& Welty Peachey, 2011). However, because an employee's manager is often the most redundant point of contact a person has with the overall corporate structure, the style of leadership deployed by the manager must vary based on the individual needs of the follower.

\section{Research Design}

The qualitative research was designed to be correlational and designed to show potential relationships between job satisfaction and the effectiveness of leadership styles. The Vannsimpco Leadership Survey (VLS) was used to capture perceived leadership style and the Minnesota Satisfaction Questionnaire (MSQ) was chosen to address job satisfaction, both intrinsic and extrinsic. Job satisfaction was the dependent variable while the leadership styles were independent.

\section{Data Collection Sources}

The membership lists of national and regional professional associations were used to solicit surveys from random and anonymous participants across the United States. Data obtained was used anonymously. Participants received an adaptation of the Vannsimpco Leadership Survey (VLS) and the Minnesota Satisfaction Questionnaire (MSQ) through the online distribution. The data was filtered to identify information including gender, education, years of experience, tenure within the current position, and other demographic data. The results were then generalized to the population of economic development professionals.

\section{Data Analysis Techniques}

The Vannsimpco Leadership Survey was used to identify the following preferred leadership styles transformational, transactional, laissez-faire leadership, democratic, or autocratic leadership styles. The VLS was also used to identify a hybrid or a combination of the styles.

The MSQ survey was designed to address 20 job satisfaction categories and used Likert-type responses that provide for factor analysis of the data that results in two sub-factors: Intrinsic and Extrinsic satisfaction. In addition, the two sub-factors scored on the MSQ were combined to provide a raw data score for general satisfaction that indicates the respondent's current level of job satisfaction based on 20 categories that included participants such as recognition, culture, utilization, and advancement opportunities. Each of the 20 factors contributed to an overall job satisfaction score based on the rating system of the MSQ. An Analysis of Variance (ANOVA) test was then applied to determine if there were significant differences among the leadership styles. A Tukey's Honestly Significant Difference test (Tukey's HSD) was used to test for significance between the means of the 36 leadership style pairs.

A regression test was used to identify a correlation between the leadership style and job satisfaction score (Spatz, 2008). A single factor, one-way ANOVA was then used to analyze the job satisfaction scores along the five thresholds identified in the survey Results were 
compiled and analyzed utilizing Microsoft Excel's data analysis tool. An alpha level of .05 was established for all statistical tests to identify significance.

\section{Description of the Participants}

The survey was distributed randomly and anonymously to adults working in the economic development profession through email and then administered online. The respondent population consisted of 92 economic development professionals randomly assigned across the United States. Of the 92 participants, 43.5 percent $(N=40)$ were female and 56.5 percent $(N=$ 52) were male. Forty-eight total respondents, just more than 52 percent, were 35 to 54 years of age.

Half of the 92 respondents reported having a master's degree, 31 respondents (33.7 percent) possessed a bachelor's degree, four had an associate degree, and six possessed a high school education. While most professionals were mid-career age, 47 of the 92 total respondents (51 percent) had been in their current job six years or less. One-third of the 92 respondents ( 31 total, or 33.7 percent) reported between seven and 15 years of tenure at their current position while 14 of the 92 (15.2 percent) had 16 or more years of employment with their current organization.

\section{Analyses of the Research Question Results}

All participants began the study with demographic questions that established age, gender, education, and length of current employment. A hybrid of the VLS and MSQ was then administered to 92 participants. Scores were analyzed using a Likert scale of: $1=$ strongly disagree, 2 = disagree, $3=$ neutral, $4=$ agree, and $5=$ strongly agree.

Questions five through 33 of the survey represented the VLS portion of the research. Within these 27 VLS questions there were nine categories (three questions per category) of leadership: Transactional, Democratic, Autocratic, Autocratic-Transformational, Autocratic-Transactional, Democratic-Transformational, Democratic-Transactional, Transformational, and Laissez-faire. Questions 34 through 54 represented the MSQ section of the research. The MSQ yielded three satisfaction score categories: general satisfaction, intrinsic, and extrinsic. The scores for questions 5, 6, 12, 13, 14, and 19 were representative of the respondent's extrinsic satisfaction, the remaining questions were used for an intrinsic satisfaction score. All of the questions in the MSQ portion of the survey were used for a raw general satisfaction score out of a possible 100 in accordance with the MSQ manual (MSQ, 1967).

In total, the 92 participants in the study reported a mean satisfaction score of 77.73 out of a possible 100. These results indicate that the industry on a whole has high job satisfaction since a score of 75 and above is considered high job satisfaction (MSQ, 1967).

Analysis of Research Question One: Is there a significant difference among perceived leadership styles in the field of economic development? A single factor, one-way ANOVA was conducted to analyze the participants' responses to the survey. The ANOVA calculations revealed a significant difference among the leadership styles of Transactional $(M=3.14)$, 
Democratic $(M=3.69)$, Autocratic $(M=3.55)$, Autocratic-Transformational $(M=3.41)$, Autocratic-Transactional $(M=2.77)$, Democratic-Transformational $(M=3.64)$, Democratic-Transactional $(M=3.16)$, Transformational $(M=3.51)$, and Laissez-Faire $(M=$ $3.02),(F[8,819]=12.36, p<.001)$.

The statistical analysis of data in the VLS portion of the survey indicated there was situational leadership with no preference among the top five leadership styles of Democratic $(M=3.69)$, Autocratic $(M=3.55)$, Autocratic-Transformational $(M=3.41)$, Democratic-Transformational $(M=3.64)$, and Transformational $(M=3.51)$.

The analysis of data in the VLS portion of the survey through the ANOVA and Tukey's HSD indicated there was situational leadership with no preference among the top five leadership styles of Democratic, Autocratic, Autocratic-Transformational, Democratic-Transformational, and Transformational leadership.

Analysis of Research Question Two: Is there a significant relationship between leadership style and job satisfaction? When tallying raw scores of the MSQ portion of the survey, possible scores ranged from 20 to 100 total points. Of the 92 respondents to the survey, just two scored below the 50-point threshold that indicated general satisfaction. Both scores were 48 points. As a whole, because the average score for the group was 77.73 , exceeding the 75-point threshold for high job satisfaction, the industry of economic development professionals would be considered to have a high degree of job satisfaction (MSQ, 1967).

Results indicated that there was situational leadership present with no preference among the top five leadership styles. Regression tests examining the job satisfaction score and the mean for each of the top five leadership styles was conducted using a regression test that resulted in a Pearson's Product Moment Correlation $r$. The regression test was used to identify a correlation between the leadership style and job satisfaction score.

According to the regression test there was a significant relationship between job satisfaction and the Democratic leadership style mean score $(M=3.69)$ for each participant, $(r=.64, F[1$, $90]=60.95, p<.01)($ Spatz, 2008). Table 2 shows the results of the regression test.

Table 2. Democratic Leadership Style Regression Summary

\begin{tabular}{|c|c|c|c|c|}
\hline \multicolumn{2}{|c|}{ Regression Statistics } & & & \\
\hline Multiple R & 0.635422925 & & & \\
\hline R Square & 0.403762294 & & & \\
\hline Adjusted R Square & 0.397137431 & & & \\
\hline Standard Error & 9.636840939 & & & \\
\hline Observations & 92 & & & \\
\hline \multirow[t]{2}{*}{ ANOVA } & & & & \\
\hline & $d f$ & SS & MS & $F$ \\
\hline Regression & 1 & 5660.023 & 5660.023 & 60.946 \\
\hline
\end{tabular}

The interpretation of the test result should be considered since the correlation proved to be significant using the regression test. According to rules for interpreting effect sizes proposed 
by Cohen, a small or less significant effect would result in an $r$ statistic of 0.20 , a medium effect would be approximately 0.50 , and a large effect score would be 0.80 (Spatz, 2008). The $r$ coefficient score of 0.64 for Democratic leadership indicates that there was a medium to large effect size of significance.

The regression test also indicated there was a significant relationship between job satisfaction and the Autocratic leadership style mean score $(M=3.55)$ for each participant, $(r=.45, F[1$, $90]=22.34, p<.01)($ Spatz, 2008). Table 3 shows the results of the regression test. The $r$ coefficient score of 0.45 for Autocratic leadership indicates that there was a medium effect size of significance.

Table 3. Autocratic Leadership Style Regression Summary

\begin{tabular}{|c|c|c|c|c|c|}
\hline \multicolumn{2}{|c|}{ Regression Statistics } & & & & \\
\hline Multiple R & 0.445921457 & & & & \\
\hline R Square & 0.198845946 & & & & \\
\hline Adjusted R Square & 0.189944234 & & & & \\
\hline Standard Error & 11.1707669 & & & & \\
\hline Observations & 92 & & & & \\
\hline \multicolumn{6}{|l|}{ ANOVA } \\
\hline & $d f$ & SS & MS & $F$ & Significance $F$ \\
\hline Regression & 1 & 2787.464 & 2787.464 & 22.33794 & $8.4 E-06$ \\
\hline Residual & 90 & 11230.74 & 124.786 & & \\
\hline Total & 91 & 14018.21 & & & \\
\hline
\end{tabular}

According to the regression test there was a significant relationship between job satisfaction and the Autocratic-Transformational leadership style mean score $(M=3.41)$ for each participant, $(r=.54, F[1,90]=36.71, p<.01)($ Spatz, 2008). Table 4 shows the results of the regression test. The $r$ coefficient score of 0.54 for Autocratic-Transformational leadership indicates that there was a medium effect size of significance.

Table 4. Autocratic-Transformational Leadership Style Regression Summary

\begin{tabular}{|c|c|c|c|c|c|}
\hline \multicolumn{2}{|c|}{ Regression Statistics } & & & & \\
\hline Multiple R & 0.538241 & & & & \\
\hline R Square & 0.289703 & & & & \\
\hline Adjusted R Square & 0.281811 & & & & \\
\hline Standard Error & 10.51829 & & & & \\
\hline Observations & 92 & & & & \\
\hline \multicolumn{6}{|l|}{ ANOVA } \\
\hline & $d f$ & SS & MS & $F$ & Significance $F$ \\
\hline Regression & 1 & 4061.115 & 4061.115 & 36.70754 & $3.13715 \mathrm{E}-08$ \\
\hline Residual & 90 & 9957.092 & 110.6344 & & \\
\hline Total & 91 & 14018.21 & & & \\
\hline
\end{tabular}

According to the regression test there was a significant relationship between job satisfaction and the Democratic-Transformational leadership style mean score $(M=3.64)$ for each participant, $(r=.67, F[1,90]=75.06, p<.01)($ Spatz, 2008). Table 5 shows the results of the regression test. The $r$ coefficient score of 0.67 for Democratic-Transformational leadership indicates that there was a medium to large effect size of significance. 
Table 5. Autocratic-Transformational Leadership Style Regression Summary

\begin{tabular}{|c|c|c|c|c|c|}
\hline \multicolumn{2}{|c|}{ Regression Statistics } & & & & \\
\hline Multiple R & 0.674342 & & & & \\
\hline R Square & 0.454737 & & & & \\
\hline Adjusted R Square & 0.448679 & & & & \\
\hline Standard Error & 9.21569 & & & & \\
\hline Observations & 92 & & & & \\
\hline \multicolumn{6}{|l|}{ ANOVA } \\
\hline & $d f$ & SS & MS & $F$ & Significance $F$ \\
\hline Regression & 1 & 6374.602 & 6374.602 & 75.05806 & $1.72386 \mathrm{E}-13$ \\
\hline Residual & 90 & 7643.605 & 84.92894 & & \\
\hline Total & 91 & 14018.21 & & & \\
\hline
\end{tabular}

According to the regression test there was a significant relationship between job satisfaction and the Transformational leadership style mean score $(M=3.51)$ for each participant, $(r=.66$, $F[1,90]=70.79, p<.01)($ Spatz, 2008). Table 6 shows the results of the regression test. The $r$ coefficient score of 0.66 for Transformational leadership indicates that there was a medium to large effect size of significance.

Table 6. Autocratic-Transformational Leadership Style Regression Summary

\begin{tabular}{|c|c|c|c|c|c|}
\hline \multicolumn{2}{|c|}{ Regression Statistics } & & & & \\
\hline Multiple R & 0.663534 & & & & \\
\hline R Square & 0.440278 & & & & \\
\hline Adjusted R Square & 0.434059 & & & & \\
\hline Standard Error & 9.337084 & & & & \\
\hline Observations & 92 & & & & \\
\hline \multicolumn{6}{|l|}{ ANOVA } \\
\hline & $d f$ & SS & MS & $F$ & Significance F \\
\hline Regression & 1 & 6171.905 & 6171.905 & 70.79404 & $5.68464 \mathrm{E}-13$ \\
\hline Residual & 90 & 7846.302 & 87.18113 & & \\
\hline Total & 91 & 14018.21 & & & \\
\hline
\end{tabular}

Of the nine leadership styles identified in the VLS, the five most common styles identified by those respondents with a job satisfaction score above the highly satisfied threshold were the Democratic, Autocratic, Democratic-Transformational, Autocratic-Transformational, and Transformational leadership styles. When conducting a regression data analysis test for each leadership style mean with the job satisfaction scores, each test concluded that there is a significant relationship between leadership style and job satisfaction.

\section{Discussion}

The current unemployment trend as a result of COVID-19 will have impacts on the US workforce for years to come. How organizations are constructed, and the manner in which employees are lead becomes vital as organizations across the country rebuild their workforce. As organizations call workers back, or seek to rebuild their workforce through new methods, leadership and job satisfaction become vital to the attraction and retention of talented employees. On the last day of November 2019, there were nearly seven million unfilled jobs 
in the United States (Department of Labor, 2020). During that same month, 5.6 million Americans in the workforce left employment with one organization to be hired at another, a slight decrease from the highest new hires figure ever reported of 5.9 million hires in August 2018 (Department of Labor, 2020). Over the 12-month period from December 2018 to November 2019, 69.8 million Americans were hired into new jobs (Department of Labor, 2020). With the United States reporting more unfilled jobs than there are unemployed workers, the demand for talent in the workforce is at unprecedented levels. This trend indicates fluidity in the job market that makes understanding the relationship between leadership and job satisfaction vital. Research has indicated that leadership can have a positive and significant effect on an employee's job satisfaction and performance (Erawan, Agung, \& Martini, 2018). Research has shown that those employees that reported a lack of job satisfaction identify manager relationships that lack effective communication or acknowledgement of tangible problems (Atefi et al., 2014). The purpose of this research was to identify common themes in the perceptions of leadership within the context of the economic development profession while also exploring the relationship between leadership styles and job satisfaction.

\section{Practical Significance}

The results of the survey indicated that there was situational leadership with no preference among the top five leadership styles from their current supervisor.

Research Question One: Is there a significant difference among perceived leadership styles in the field of economic development? A single factor, one-way ANOVA showed a statistically significant difference among the perceived leadership styles. The ANOVA showed that respondents perceived some leadership styles more often than others. The most common leadership styles, sorted in descending order by their identified means, were as follows: Democratic $(M=3.69)$, Democratic-Transformational $(M=3.64)$, Autocratic $(M=3.55)$, Transformational $(M=3.51)$, Autocratic-Transformational $(M=3.41)$, Democratic-Transactional $(M=3.16)$, Transactional $(M=3.14)$, Laissez-Faire $(M=3.02)$, and Autocratic-Transactional $(M=2.77)$.

The two most common leadership styles, Democratic and Democratic-Transformational, are leadership styles that value input from followers while striving to empower their followers to achieve future growth from an organizational standpoint (Democratic) and a personal standpoint (Transformational) (Vann, Simpson, \& Coleman, 2014). However, the third most common leadership style identified by the ANOVA exists in conflict with the first two. Autocratic leadership involves leaders who "concentrate all decision-making with themselves" (Vann, Simpson, \& Coleman, 2014, p. 32). Where democratic leaders blur the lines of hierarchical structure, autocratic leaders embrace the clear delineation of organizational power. These top three leadership styles seemingly exist in conflict with each other, yet the economic development profession as a whole averaged scores that demonstrated effectively high job satisfaction. This led to the examination of differences between the perceived styles.

The comparison of leadership styles was conducted with a Tukey's HSD test. The test 
compared 36 leadership style combinations and indicated a significant difference in 14 pairs, but not the five independent leadership styles. The culmination of the data analysis conducted under the first research question indicated that there was not a single perceived leadership style identified by the economic development professionals. The data analysis also indicated that there was situational leadership with no preference among the top five leadership styles of Democratic $(M=3.69)$, Autocratic $(M=3.55)$, Autocratic-Transformational $(M=3.41)$, Democratic-Transformational $(M=3.64)$, and Transformational $(M=3.51)$.

Research Question Two: Is there a significant relationship between leadership style and job satisfaction? While there was not a single perceived leadership style that was prevalent amongst the economic development profession, the data collected in this research showed a relationship between job satisfaction and leadership style for each of the top five perceived leadership styles. The average job satisfaction score of all 92 respondents was 77.73, above the 75-point threshold for high job satisfaction (MSQ, 1967). A regression test was performed to determine if a correlation existed between the top five perceived leadership styles of Democratic $(M=3.69)$, Autocratic $(M=3.55)$, Autocratic-Transformational $(M=3.41)$, Democratic-Transformational $(M=3.64)$, and Transformational $(M=3.51)$, and the job satisfaction score. Each individual regression test indicated that there was a moderate to largely significant relationship between the top five perceived leadership styles and job satisfaction.

However, the subset of respondents who identified just one dominant perceived leadership style and showed no correlation between leadership and job satisfaction. Those respondents who perceived multiple leadership styles showed a correlation between the flexible, multi-faceted leadership approach and their job satisfaction. While the group as a whole showed a job satisfaction score average above the high satisfaction threshold, it could be that those respondents who perceived just one single dominant leadership style were able to anticipate their leaders' expectations and establish job satisfaction through intrinsic motivations that corresponded with their job responsibilities and roles.

Interestingly, while there were eight respondents in the 50 to 60 -point job satisfaction range ( 8.7 percent), the only two respondents to score below the 50-point job satisfaction threshold both reported Laissez-Faire for being their supervisor's dominant style. Both individuals were male, age 45 to 54 years. One had a master's degree with one to three years with their current employer, while the other had a high school education and four to six years with the current employer.

\section{Limitations of the Study}

The greatest limitation of this study was the population size of the sample. The survey was distributed randomly to 2,603 anonymous economic development professionals. Less than four percent completed the survey. While there were no geographic restrictions, the results may or may not be generalized to the larger economic development profession in the United States. The survey was administered during a three-week period, during which potential participants were emailed the informed consent letter and survey up to three times. Because the survey was distributed anonymously and randomly, there was no method of constricting 
respondents to a limit of just one response. There was also the limitation of time, some potential respondents may not have been available to participate during the data collection period. The following section discusses implications of the findings.

\section{Implications}

This study addresses the gap in data available for the economic development profession as a whole. It provides a piece of the foundation for future studies to move forward conducting research that explores the job satisfaction and reasons why educated, professional employees leave employment in which they are currently highly satisfied. Future studies can focus on the intrinsic and extrinsic factors of job satisfaction, and how leadership styles relate to the motivations of educated professionals in the economic development industry and related fields. The findings of this research can be used to advance the knowledge of human capital development not only in the economic development professional field, but also in similar professions that rely on educated workers. Replicating the same study in similar fields can produce cross-sector analysis opportunities that might address the broader population by identifying factors that increase job satisfaction. This study was broad in nature, but can be duplicated and refined to target specific demographics of future research. The research above demonstrates it is imperative that future leaders understand the dynamic of their workforce as organizations across all sectors struggle to attract and retain talented workers.

\section{Conclusion}

The challenge of leadership studies in general is to disentangle cause from effect. The purpose of this study was to identify a common perceived leadership style in the economic development profession, determine if there was a relationship between leadership and job satisfaction, and identify the monetary threshold which generally satisfied employees would leave their current employment. The results of the study found that while the economic development profession as a whole has highly satisfied employees, there was not a single perceived leadership style present. While Democratic, Autocratic, Autocratic-Transformational, Democratic-Transformational, and Transformational were the five most common perceived leadership styles, Laissez-Faire and Autocratic-Transactional were perceived significantly less than the others.

When considering the respondent population as a whole, the data showed that the employees were extremely educated and very satisfied in their profession in general. Overall, the population of respondents are educated. Eighty-nine percent of respondents possess a bachelor's degree or higher, substantially more than the national average of 34 percent of US workers (US Census, 2017). The data also showed that there was a significant relationship between leadership style and job satisfaction. While no single leadership style was identified, the economic development profession was highly satisfied as a group. Interestingly, the group of respondents willing to leave their current position for just a ten percent increase in pay were the least satisfied. The data demonstrated that there was a significant relationship between lower job satisfaction and an employee's willingness to accept a nominal increase to change positions. 
Employees that have positive job satisfaction and trust their leaders within the organization are more efficient and effective in their job performance (Brown, Gray, McHardy, \& Taylor, 2015). Effective and efficient employees are an organization's most important commodity. Managers can attract new workers and/or lessen the employees' desire to seek alternative employment through effective leadership. Therefore, it is imperative for leaders to understand the context and composition of their staff as they seek to maintain the satisfaction of their employees through effective leadership.

\section{References}

Atefi, N., Abdullah, K. L., Wong, L. P., \& Mazlom, R. (2014). Factors influencing registered nurse's perception of their overall job satisfaction: a qualitative study. International Nursing Review, 61(3), 352-360. https://doi.org/10.1111/inr.12112

Avolio, B. J., Zhu, W., Koh, W., \& Bhatia, P. (2004). Transformational leadership and organizational commitment: Mediating role of psychological empowerment and moderating role of structural distance. Journal of Organizational Behavior, 25(8), 951-968. https://doi.org/10.1002/job.283

Bass, B. M. (1990). From transactional to transformational leadership: Learning to share the vision. Organizational Dynamics, $\quad 18(3), \quad 19-31$. https://doi.org/10.1016/0090-2616(90)90061-S

Bass, B. M., Avolio, B. J., Jung, D. I., \& Berson, Y. (2003). Predicting unit performance by assessing transformational and transactional leadership. Journal of Applied Psychology, 88(2), 207-218. https://psycnet.apa.org/doi/10.1037/0021-9010.88.2.207

Bogler, R. (2001). The influence of leadership style on teacher job satisfaction. Educational Administration Quarterly, 37(5), 662-683. https://doi.org/10.1177\%2F00131610121969460

Braun, S., Peus, C., Weisweiler, S., \& Frey, D. (2013). Transformational leadership, job satisfaction, and team performance: A multilevel mediation model of trust. The Leadership Quarterly, 24(1), 270-283. https://doi.org/10.1016/j.leaqua.2012.11.006

Brown, S., Gray, D., McHardy, J., \& Taylor, K. (2015). Employee trust and workplace performance. Journal of Economic Behavior \& Organization, 116, 361-378. https://doi.org/10.1016/j.jebo.2015.05.001

Daft, G. (2011). The Leadership Experience. Stamford: Cengage Learning. https://doi.org/10.1080/08832323.2014.921593

Deichmann, D., \& Stam, D. (2015). Leveraging transformational and transactional leadership to cultivate the generation of organization-focused ideas. The Leadership Quarterly, 26(2), 204-219. https://doi.org/10.1016/j.leaqua.2014.10.004

Erawan, I., Agung, A., \& Martini, L. (2018). The Effect of Leadership and Organizational Commitment to Performance of Employees with Working Satisfaction as Intervening Variables in Tanah Lot DTW Management Office. International Journal of Contemporary Research and Review, 9(10), 21096-21108. https://doi.org/10.15520/ijcrr/2018/9/10/613 
Harter, J., \& Adkins, A. (2015). Employees want a lot more from their managers. Gallup Business Journal. Retrieved April 12, 2018 from: http://news.gallup.com/businessjournal/182321/employees-lot-managers.aspx

Harter J. K., Schmidt F. L., Asplund J. W., Killham E. A., \& Agrawal S. (2010). Causal impact of employee work perceptions on the bottom line of organizations. Perspectives on Psychological Science, 5, 378-389. https://doi.org/10.1177\%2F1745691610374589

Hartog, D. N., Muijen, J. J., \& Koopman, P. L. (1997). Transactional versus transformational leadership: An analysis of the MLQ. Journal of Occupational and Organizational Psychology, 70(1), 19-34. https://doi.org/10.1111/j.2044-8325.1997.tb00628.x

Hom, P. W., Lee, T. W., Shaw, J. D., \& Hausknecht, J. P. (2017). One hundred years of employee turnover theory and research. Journal of Applied Psychology, 102(3), 530-545. https://psycnet.apa.org/doi/10.1037/ap10000103

Jacquart, P., \& Antonakis, J. 2015. When does charisma matter for top-level leaders? Effect of attributional ambiguity. Academy of Management Journal, 58(4), 1051-1074. https://doi.org/10.5465/amj.2012.0831

Johnson, J., \& Ng, E. S. (2016). Money talks or Millennials walk: The effect of compensation on nonprofit millennial workers' sector-switching intentions. Review of Public Personnel Administration, 36(3), 283-305. https://doi.org/10.1177\%2F0734371X15587980

Kumar, R., \& Eng, K. G. (2012). Perceived organizational commitment and its impact to the turnover intention: A correlation analysis. Journal of Global Business and Economics, 4, $40-57$.

Maidani, E. A. (1991). Comparative study of Herzberg's two-factor theory of job satisfaction among public and private sectors. Public Personnel Management, 20(4), 441-448. https://psycnet.apa.org/doi/10.1177/009102609102000405

Martin, R., \& Epitropaki, O. (2001). Role of Organizational Identification on Implicit Leadership Theories (ILTS), Transformational leadership and work attitudes. Group Process Intergroup Relations, 4, 247-262. https://doi.org/10.1177\%2F1368430201004003005

McKeown, E. (2010). Retention in the upswing. Training \& Development, 22(7), 96-106.

Ohio Department of Jobs and Family Services (2018). Labor Market Dynamics: The Effects of Job Postings and Labor Market Activities on Total Employment. Retrieved from: http://ohiolmi.com/research/publications/LaborMarketDynamics_1.pdf

Park, T. Y., \& Shaw, J. D. (2013). Turnover rates and organizational performance: A meta-analysis. Journal of Applied Psychology, 98(2), 268-309. https://doi.org/10.1037/a0030723

Pillai, R., Schriesheim, C. A., \& Williams, E. S. (1999). Fairness perceptions and trust as mediators for transformational and transactional leadership: A two-sample study. Journal of Management, 25(6), 897-933. https://doi.org/10.1016/S0149-2063(99)00031-8 


\section{Al Macrothink}

Journal of Management Research ISSN 1941-899X 2020, Vol. 12, No. 3

Reina, C. S., Rogers, K. M., Peterson, S. J., Byron, K., \& Hom, P. W. (2018). Quitting the Boss? The Role of Manager Influence Tactics and Employee Emotional Engagement in Voluntary Turnover. Journal of Leadership \& Organizational Studies, 25(1), 5-18. https://doi.org/10.1177\%2F1548051817709007

Rowold, J. (2014). Instrumental leadership: Extending the transformational-transactional leadership paradigm. German Journal of Research in Human Resource Management, 28(3), 367-390. https://doi.org/10.1177\%2F239700221402800304

Spatz, C. (2008). Basic statistics: Tales of distributions (8th ed.). Thomson Wadsworth.

Spector, P. E. (1997). Job Satisfaction: Application, Assessment, Causes, and Consequences. Thousand Oaks, Calif: SAGE Publications, Inc. http://dx.doi.org/10.4135/9781452231549

US Bureau of Labor Statistics (2020). Quits levels and rates by industry and region, seasonally adjusted. Retrieved from: https://www.bls.gov/news.release/jolts.t04.htm

US Bureau of Labor Statistics (2020). Job Openings and Labor Turnover Summary - January 2020. Retrieved from: https://www.bls.gov/news.release/pdf/empsit.pdf

US Census (2017) Educational Attainment in the United States: 2017. United States Census Bureau. Retrieved from: https://www.census.gov/data/tables/2017/demo/education-attainment/cps-detailed-tables.html

Vogel, R. M., \& Mitchell, M. S. (2017). The motivational effects of diminished self-esteem for employees who experience abusive supervision. Journal of Management, 43(7), 2218-2251. https://doi.org/10.1177\%2F0149206314566462

Waldman, D. A., Carter, M. Z., \& Hom, P. W. (2015). A multilevel investigation of leadership and turnover behavior. Journal of Management, 41(6), 1724-1744. https://doi.org/10.1177\%2F0149206312460679

Wells, J. E., \& Welty Peachey, J. (2011). Turnover intentions: do leadership behaviors and satisfaction with the leader matter? Team Performance Management: An International Journal, 17(1/2), 23-40. https://doi.org/10.1108/13527591111114693

Welty Peachey, J., J. Burton, L., \& E. Wells, J. (2014). Examining the influence of transformational leadership, organizational commitment, job embeddedness, and job search behaviors on turnover intentions in intercollegiate athletics. Leadership \& Organization Development Journal, 35(8), 740-755. https://doi.org/10.1108/LODJ-10-2012-0128

\section{Copyright Disclaimer}

Copyright for this article is retained by the author(s), with first publication rights granted to the journal.

This is an open-access article distributed under the terms and conditions of the Creative Commons Attribution license (http://creativecommons.org/licenses/by/3.0/). 